\title{
The genus Hyalomma Koch, 1844. IV. Redescription of all parasitic stages of $H$. (Euhyalomma) lusitanicum Koch, 1844 and the adults of H. (E.) franchinii Tonelli Rondelli, 1932 (Acari: Ixodidae) with a first description of its immature stages
}

\author{
Dmitry A. Apanaskevich ${ }^{1}$, Maria Margarida Santos-Silva ${ }^{2}$ and Ivan G. Horak ${ }^{3}$ \\ ${ }^{1}$ United States National Tick Collection, Institute of Arthropodology and Parasitology, Georgia Southern University, Statesboro, \\ GA 30460-8056, USA; \\ ${ }^{2}$ Centre for Vector and Infectious Diseases Research, National Institute of Health Dr. Ricardo Jorge, Av. Padre Cruz, $1649-016$ \\ Lisbon, Portugal; \\ ${ }^{3}$ Division of Parasitology, Onderstepoort Veterinary Institute, Onderstepoort, 0110, South Africa, and Department of Zoology \\ and Entomology, University of the Free State, Bloemfontein, 9301, South Africa
}

Key words: Hyalomma (Euhyalomma) lusitanicum, Hyalomma (Euhyalomma) franchinii, systematics, male, female, nymph, larva, distribution, hosts

\begin{abstract}
Hyalomma (Euhyalomma) lusitanicum Koch, 1844 and Hyalomma (Euhyalomma) franchinii Tonelli Rondelli, 1932 are amongst the most poorly studied of those species within the genus Hyalomma Koch, 1844 that are restricted to the Mediterranean region. No comprehensive morphological study has been done to date, and the immature stages of $H$. (E.) franchinii have not been described. Here all the parasitic stages of $H$. (E.) lusitanicum and the adults of $H$. (E.) franchinii are redescribed, and the immature stages of the latter species are described for the first time. Data on hosts, geographic distribution and disease relationships are provided.
\end{abstract}

Hyalomma (Euhyalomma) lusitanicum Koch, 1844 was originally described as an independent species (Koch 1844); later, however, Neumann (1899, 1901) considered it to be a variety of Hyalomma aegyptium (Linnaeus, 1758). Senevet (1922) and Schulze and Schlottke (1930) regarded it as a polymorphic species and described various subspecies that are now considered synonyms. Delpy (1949) synonymized $H$. (E.) lusitanicum under the composite species Hyalomma excavatum Koch, 1844 and Hoogstraal (1956) supported this. At approximately the same time, Feldman-Muhsam (1954) considered that the taxonomic status of this species was not unequivocal. Tendeiro (1955), however, recognized $H$. (E.) lusitanicum as a valid species and redescribed the male and female. After they had studied numerous specimens from the western Mediterranean region, Hoogstraal and Kaiser (1959) supported Tendeiro's point of view and provided a differential diagnosis for the adults.

Hyalomma (Euhyalomma) franchinii Tonelli Rondelli, 1932 was originally described as a subspecies of Hyalomma tunesiacum Schulze et Schlottke, 1930, namely $H$. tunesiacum franchinii (Tonelli Rondelli 1932). Thereafter several authors synonymized $H$. tunesiacum franchinii under the composite species $H$. excavatum (Delpy 1949, Feldman-Muhsam 1954, Tendeiro 1955). Later Hoogstraal (1956) described the adults of a Hyalomma which he tentatively named Hyalomma sp. no. 1 near excavatum. Subsequent comparison of the latter species with type specimens of $H$. tunesiacum franchinii led Hoogstraal and Kaiser (1958b) to conclude that they are the same species. They then reestablished $H$. (E.) franchinii as a full species and supplied differential diagnoses for the male and female.

The phylogenetic position of both $H$. lusitanicum and $H$. franchinii is unclear. Hoogstraal and Kaiser (1959) placed these species in the Hyalomma anatolicum group of species, a group that contains both $H$. anatolicum Koch, 1844 and $H$. excavatum. Both $H$. (E.) lusitanicum and $H$. (E.) franchinii resemble $H$. (E.) excavatum, making it difficult to differentiate the adults of these species. Specific identification of the immature stages has to date been impossible.

The main purpose of the current study is to illustrate and to describe all the parasitic stages of both species in detail in a single publication. This should assist parasitologists, epidemiologists, virologists and others with the identification of these ticks, which may be involved in the transmission of a number of disease agents in southern Europe and North Africa.

\section{MATERIALS AND METHODS}

A total of 87 males, 156 females, 50 nymphs, and 200 larvae of $H$. (E.) lusitanicum, originating from Algeria, France, Italy, Morocco, Portugal and Spain, and 165 males, 134 fe- 
males, 50 nymphs, and 200 larvae of $H$. (E.) franchinii, originating from Egypt, Israel and Tunisia, were examined in the current study. Both field-collected and laboratory-reared specimens were scrutinized. These specimens are now housed in the United States National Tick Collection (USNTC) (Institute of Arthropodology and Parasitology, Georgia Southern University, Statesboro, USA), the Field Museum of Natural History (Chicago, USA), the Zoological Institute, Russian Academy of Sciences (Saint Petersburg, Russia), the Royal Museum for Central Africa (Tervuren, Belgium), the Gertrud Theiler Tick Museum at the Onderstepoort Veterinary Institute (Onderstepoort, South Africa) and in the personal tick collection of Dr. J.B. Walker (South Africa).

The immature stages and the finer structures of the adults were mounted on glass slides and examined under a light microscope, and the macrostructures of males and females were viewed under a stereoscopic microscope. The spiracular plates of the nymphs were studied using a scanning electron microscope. Measurements for the male conscutum and female scutum are given in millimetres ( $\mathrm{mm})$, and those for the various features of the immature stages in micrometres $(\mu \mathrm{m})$. The measurements are arranged as follows: minimum - maximum (average \pm standard deviation, $\mathrm{n}=$ number of specimens measured). Their schematic layout is to be found in Apanaskevich (2003), and Apanaskevich and Horak (2006).

\section{RESULTS}

\section{Hyalomma (Euhyalomma) lusitanicum Koch, $1844 \quad$ Figs. 1-7}

Type specimens: The original description was based on specimens ( $\sigma^{\wedge}+$, not quantified) from Portugal ["Portugal", p. 222, Koch 1844]. The type specimens have apparently been lost, or have been destroyed by dermestids (Feldman-Muhsam 1954). The fact that one of us (DAA) could not find these specimens in Koch's collection at the Natural History Museum of Berlin (Germany), confirms these observations.

Synonyms (Camicas et al. 1998 with corrections): Hyalomma aegyptium var. lusitanicum Koch, 1844 sensu Neumann 1901;

Hyalomma aegyptium lusitanicum Koch, 1844 sensu Neumann 1911;

Hyalomma lusitanicum berberum Senevet, 1922;

Hyalomma lusitanicum lusitanicum Koch, 1844 sensu Senevet 1928;

Hyalomma lusitanicum cicatricosum Schulze et Schlottke, 1930;

Hyalomma savignyi iberum Schulze et Schlottke, 1930; Hyalomma iberum Schulze et Schlottke, 1930 sensu Kratz 1940;

Hyalomma excavatum lusitanicum Koch, 1844 sensu Stoker and Marmion 1955

DAA has studied the type specimen of $H$. lusitanicum cicatricosum (1§, Extremadura, [Spain]) deposited in Schulze's collection at the USNTC and concluded that it actually is Hyalomma lusitanicum, and not $H$. anatolicum as proposed by Feldman-Muhsam (1954),
Hoogstraal and Kaiser (1959) and Camicas et al. (1998). We therefore support the point of view of Tendeiro (1955). The same collection lot contains 1 + of H. lusitanicum. In addition, Schulze's collection at the USNTC contains $1 \delta$ identified as $H$. lusitanicum cicatricosum (Canary Islands, Lanzarote, [Spain], April 1901, Becker), which DAA has identified as H. lusitanicum.

Descriptions and illustrations of the adults are available in a number of publications and we consider that the most useful of these are to be found in Hoogstraal and Kaiser (1959), Tendeiro $(1955,1962)$ and FeldmanMuhsam (1962). The larva and nymph have been highly schematically described and illustrated by Senevet (1925, 1928) and Perez-Eid and Cabrita (2003).

\section{Description}

Male

Figs. 1, 2A-H, 3A

Conscutum (Fig. 1): length 3.01-4.08 (3.66 \pm 0.26 , $\mathrm{n}=63)$, width $1.99-2.72(2.41 \pm 0.16, \mathrm{n}=63)$, ratio length:width 1.40-1.68 (1.52 $\pm 0.06, \mathrm{n}=63)$; red-brown in colour; pale marbling usually clearly visible; broadly oval in shape; widest near mid-length; slight narrowing in region of spiracular plates; cervical and lateral grooves superficial, up to $1 / 3$ length of conscutum; marginal grooves short, furrow-like, extending to posterior 1/4 of conscutum; posteromedian groove separated from parma or median festoon by wart-like patch; paramedian grooves well defined; caudal field well defined, laterally demarcated by modest ridges; numerous large punctations on caudal and lateral fields, medium and small punctations dense, fairly evenly dispersed

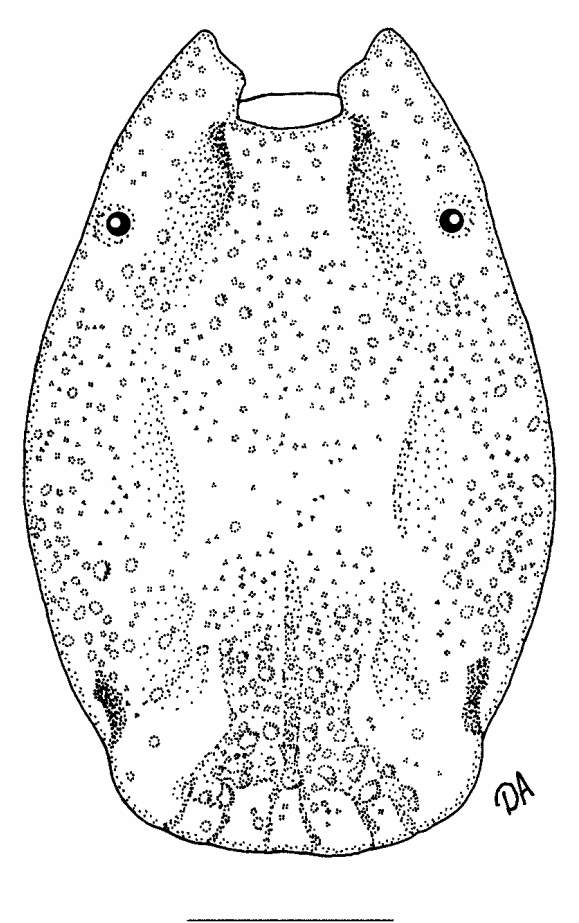

Fig. 1. Hyalomma lusitanicum, male, conscutum. Scale bar $=$ $1 \mathrm{~mm}$. 

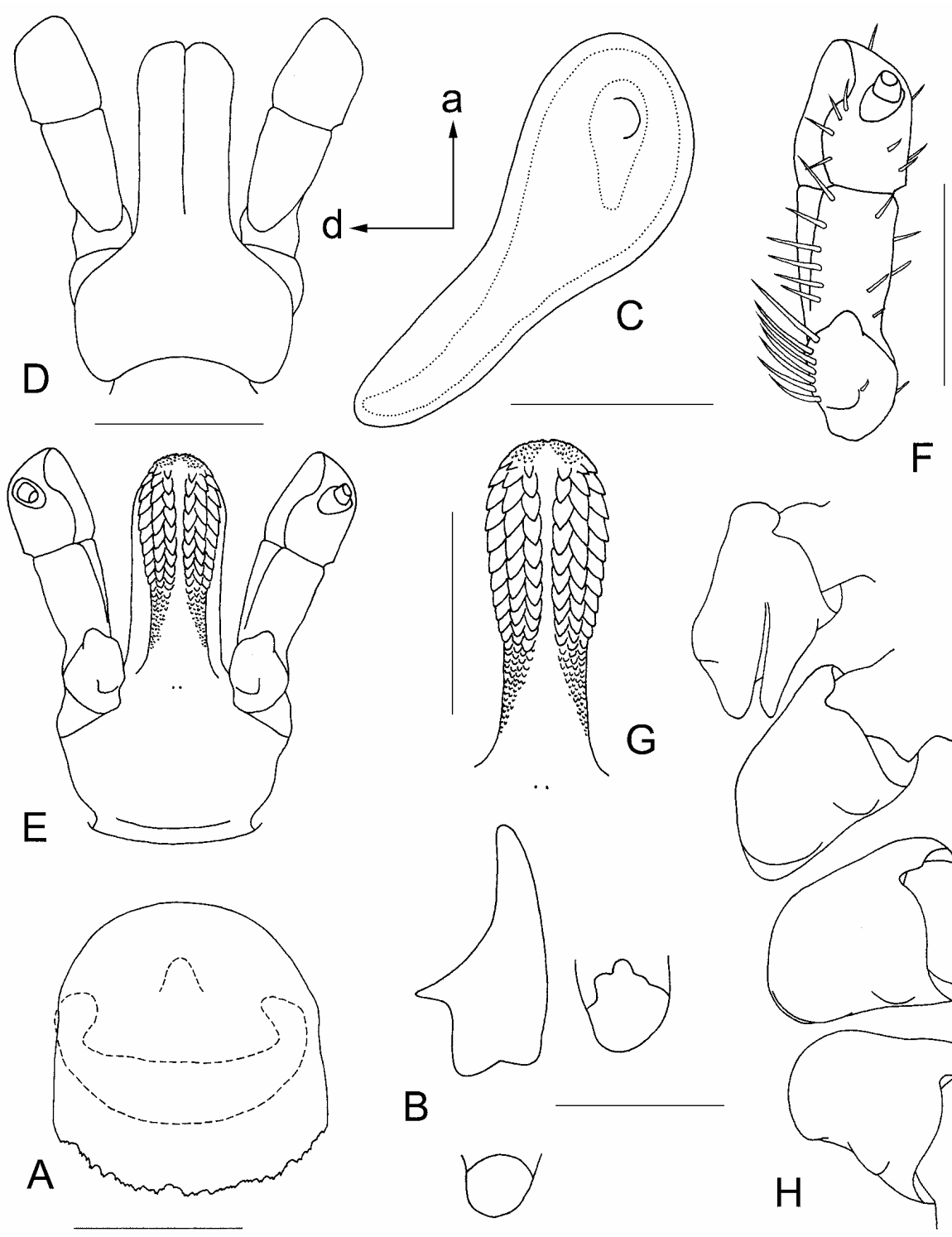

$\mathrm{F}$
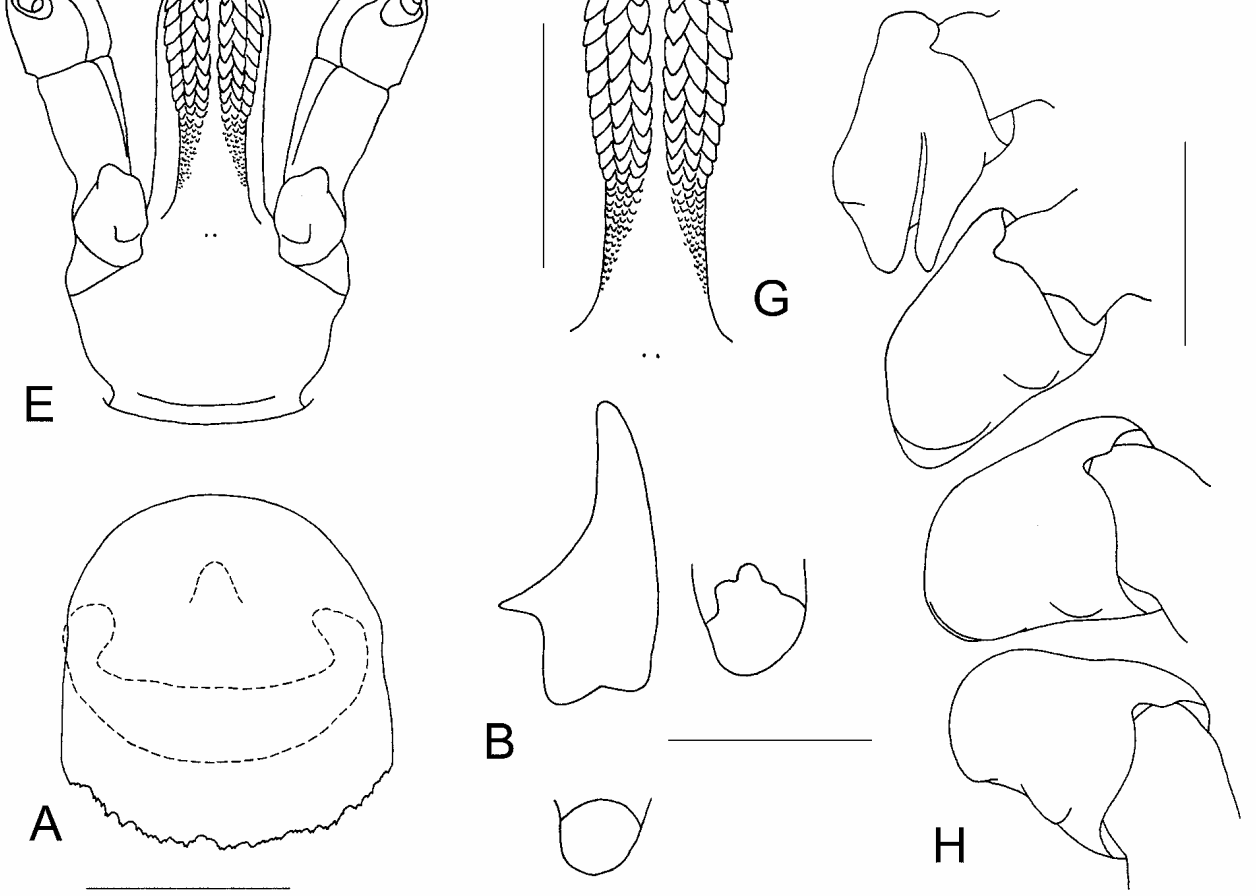

Fig. 2. Hyalomma lusitanicum, male. A - genital structures; B - anal plates; C - spiracular plate (a - anterior, d - dorsal); D gnathosoma dorsally; $\mathbf{E}$ - gnathosoma ventrally; $\mathbf{F}$ - palp ventrally; $\mathbf{G}$ - hypostome; $\mathbf{H}$ - coxae. All setation has been omitted except drawing F where only setae of segment IV have been omitted. Scale bars: $A=200 \mu \mathrm{m} ; \mathrm{B}, \mathrm{D}, \mathrm{E}, \mathrm{H}=500 \mu \mathrm{m} ; \mathrm{C}, \mathrm{F}, \mathrm{G}=$ $400 \mu \mathrm{m}$.

over conscutum, punctations denser, often contiguous on caudal field, less dense on elevations demarcating this field; parma absent or present - median festoon either well sclerotized, or only anterior half well sclerotized (generally the case), or sclerotization absent (parma); 4 or 5 distinct festoons. Genital structures (Fig. 2A) as illustrated. Anal shields (Fig. 2B): 3 pairs; adanal plates long, broad, lateral margin slightly convex, anteromedian margin concave, median projection large, posteromedian margin straight, posterior margin with concavity; subanal plates usually large and rounded. Sclerotized plaques present ventrally on median and paramedian festoons. Spiracular plate (Fig.
2C): dorsal prolongation long and clearly distinct from body of plate; perforated portion of prolongation gently curved throughout its length, relatively narrow. Circumspiracular setae sparse.

Basis capituli (Fig. 2D, E): without lateral projections; dorsal posterior margin concave; cornua modest. Palpi (Fig. 2F): segment I with more than 5 ventromedian setae. Hypostome (Fig. 2G): club-shaped; denticulate portion slightly longer than denticle-free portion (small scale-like projections posterior to last large denticle are not considered denticles).

Coxae (Fig. 2H): posteromedian and posterolateral spurs of coxa I long, subequal in length or posterolat- 


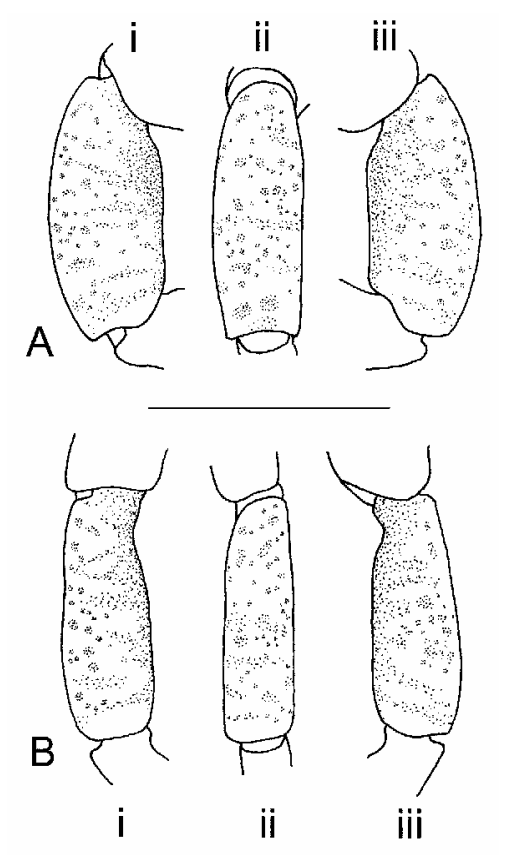

Fig. 3. Hyalomma lusitanicum, genu IV. A - male: i - lateral view, ii - dorsal view, iii - medial view; $\mathbf{B}$ - female: $\mathrm{i}$ - lateral view, ii - dorsal view, iii - medial view. Scale bar $=1 \mathrm{~mm}$.

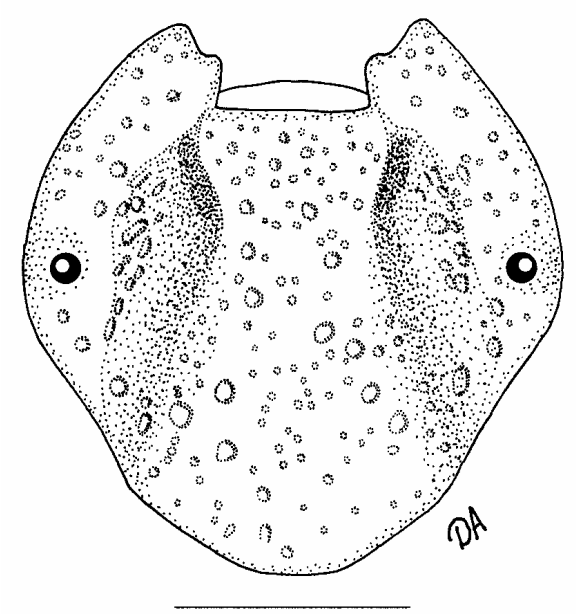

Fig. 4. Hyalomma lusitanicum, female, scutum. Scale bar $=1$ $\mathrm{mm}$.

eral spur longer than posteromedian spur, close together, tapering to apices; coxae II-IV each with distinct, broadly arcuate posterolateral spur; coxae II and III each with poorly developed, very broadly arcuate, posteromedian spur; internal spur on coxa IV distinct, triangular. Ivory-coloured enamelling diffuse on dorsal and lateral surfaces of each segment of the legs; ivorycoloured bands indistinct (Fig. 3A).

\section{Female}

Figs. 3B, 4, 5A-G

Scutum (Fig. 4): length 1.65-2.41 (2.04 $\pm 0.15, \mathrm{n}=$ $109)$, width $1.68-2.34(2.00 \pm 0.13, \mathrm{n}=109)$, ratio length:width 0.94-1.12 (1.02 $\pm 0.04, \mathrm{n}=109)$; redbrown in colour; pale marbling comprehensive; nearly as long as broad; posterolateral angles prominent; cervical and lateral grooves moderately deep, extending to posterior margin of scutum; large and medium-sized, deep punctations relatively dense, evenly distributed over scutum. Genital structures (Fig. 5A): genital aperture relatively wide, semicircular (U-shaped); vestibular portion of vagina strongly bulging. Spiracular plates (Fig. 5B): perforated portion of dorsal projection curved and relatively narrow. Circumspiracular setae sparse.

Basis capituli (Fig. 5C, D): dorsally lateral projections short, absent ventrally; dorsal posterior margin very slightly concave; dorsal cornua inconspicuous. Palpi (Fig. 5E): segment I with more than 5 ventromedian setae. Hypostome (Fig. 5F): club-shaped; denticulate portion slightly longer than denticle-free portion.

Coxae (Fig. 5G): posteromedian and posterolateral spurs of coxa I long, subequal in length or posterolateral spur longer than posteromedian spur, tapering to apices, close together; coxae II-IV each with distinct, broadly triangular posterolateral spur, with rounded apex; coxae II-IV each with poorly developed, broadly arcuate, posteromedian spur. Colouration of legs similar to that of male (Fig. 3B).

\section{Nymph}

Fig. $6 \mathrm{~A}-\mathrm{F}$

Scutum (Fig. 6A): length 536-600 (564 $\pm 17, \mathrm{n}=18)$, width $608-736(656 \pm 34, \mathrm{n}=19)$, ratio length:width $0.78-0.93(0.86 \pm 0.04, \mathrm{n}=18)$, distance between posterior margin of eyes and posterior margin of scutum 224-264 $(241 \pm 11, \mathrm{n}=18)$, width:length ratio of posterior portion of scutum 2.53-2.93 (2.73 $\pm 0.11, \mathrm{n}=18)$; posterior margin of scutum narrowly rounded; slight posterolateral depressions on either side of scutal extremity. Setae of alloscutum (Fig. 6B): narrowing to denticulate apex. Spiracular plates (Fig. 6C): oval; dorsal prolongation indistinct, short, broad, blunt at apex; submarginal row of perforations incomplete.

Basis capituli (Fig. 6D, E): length 328-384 (365 \pm $13, \mathrm{n}=16)$; width $292-320(309 \pm 8, \mathrm{n}=20)$, ratio length:width 1.11-1.22 (1.18 $\pm 0.03, \mathrm{n}=16)$. Palpi (segment II) (Fig. 6D, E): length 176-198 (185 $\pm 6, \mathrm{n}=$ $20)$, width 64-68 $(66 \pm 1, \mathrm{n}=20)$, ratio length:width 2.71-2.91 (2.78 $\pm 0.07, \mathrm{n}=20)$; palpal segment II proximally narrow, gradually expanding distally. $\mathrm{Hy}$ postome (Fig. $6 \mathrm{E})$ : length 204-250 $(226 \pm 9, \mathrm{n}=20)$, width 56-66 $(60 \pm 3, \mathrm{n}=20)$, ratio length:width 3.37$4.21(3.76 \pm 0.24, \mathrm{n}=20)$; median file with 6 or 7 large denticles; transition of denticulate portion to denticlefree portion abrupt; denticulate portion less than twice the length of the denticle-free portion.

Coxae (Fig. 6F): coxa I with long, very broad, Ushaped spurs, median spur shorter than lateral; coxae IIIV each with moderate spur, spurs conspicuously decrease in size from coxae II to IV; coxal pore present. 

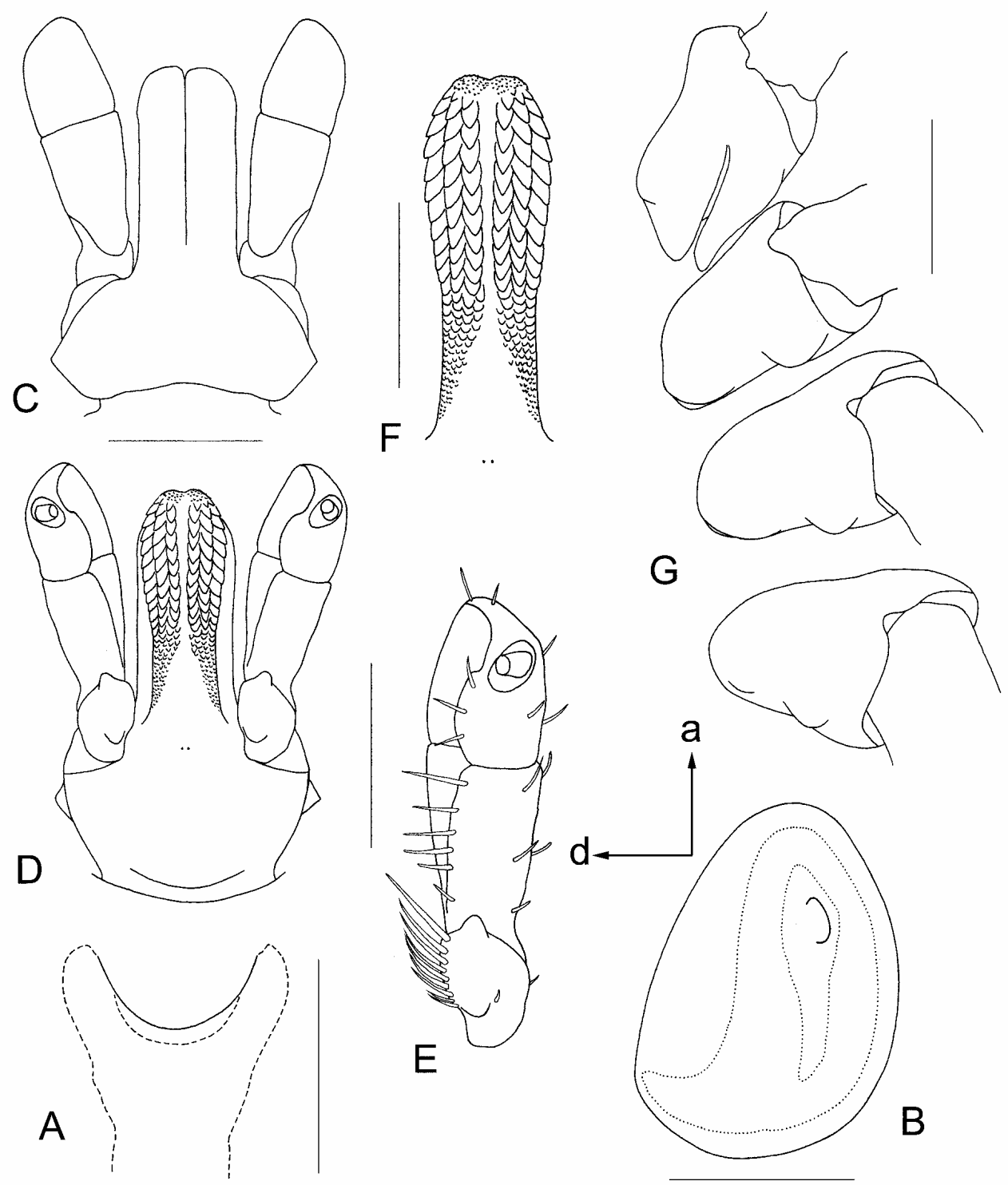

Fig. 5. Hyalomma lusitanicum, female. A - genital structures; B - spiracular plate (a - anterior, d - dorsal); $\mathbf{C}-$ gnathosoma dorsally; D - gnathosoma ventrally; $\mathbf{E}$ - palp ventrally; $\mathbf{F}$ - hypostome; $\mathbf{G}$ - coxae. All setation has been omitted except drawing E where only setae of segment IV have been omitted. Scale bars: $A=200 \mu \mathrm{m} ; \mathrm{B}, \mathrm{E}, \mathrm{F}=400 \mu \mathrm{m} ; \mathrm{C}, \mathrm{D}, \mathrm{G}=500 \mu \mathrm{m}$.

\section{Larva}

Fig. 7A-D

Scutum (Fig. 7A): length 240-272 $(254 \pm 7, \mathrm{n}=67)$, width 332-380 $(358 \pm 10, \mathrm{n}=81)$, ratio length:width $0.66-0.75(0.71 \pm 0.02, \mathrm{n}=67)$, distance from posterior margin of eyes to posterior margin of scutum 96-116 $(105 \pm 5, \mathrm{n}=67)$, width:length ratio of posterior portion 3.04-3.79 (3.42 $\pm 0.14, \mathrm{n}=67)$. Portion of scutum posterior to eyes nearly equal to $1 / 2$ of scutal length; posterior margin of scutum broadly rounded; posterolateral depressions indistinct or absent.

Basis capituli (Fig. 7B, C): width 118-140 (129 \pm 4 , $\mathrm{n}=81$ ); subhexagonal dorsally; subrectangular ventrally; apex of dorsolateral projections directed slightly anteriorly; dorsolateral projections distinct and acute from ventral aspect. Palpi (segments II and III) (Fig.
$7 \mathrm{~B}, \mathrm{C})$ : length $92-106(101 \pm 3, \mathrm{n}=81)$, width $35-40$ $(38 \pm 1, \mathrm{n}=81)$, ratio length:width $2.40-2.83(2.65 \pm$ $0.09, \mathrm{n}=81)$. Hypostome (Fig. 7C): length 82-102 (94 $\pm 4, \mathrm{n}=79)$, width $25-30(27 \pm 1, \mathrm{n}=81)$, ratio length:width $2.83-3.78(3.44 \pm 0.19, \mathrm{n}=79)$; median file with 5 large denticles; transition of denticulate portion to denticle-free portion abrupt; denticulate portion approximately $1 / 2$ of hypostome length.

Coxae (Fig. 7D): coxa I with large, subtriangular spur broadly rounded at apex; coxae II and III each with very large spur - arcuate on coxa II and triangular on coxa III. Genua I: length 102-126 $(115 \pm 4, \mathrm{n}=81)$, width $46-50(48 \pm 1, \mathrm{n}=42)$, ratio length:width 2.20 $2.56(2.41 \pm 0.08, \mathrm{n}=42)$. 


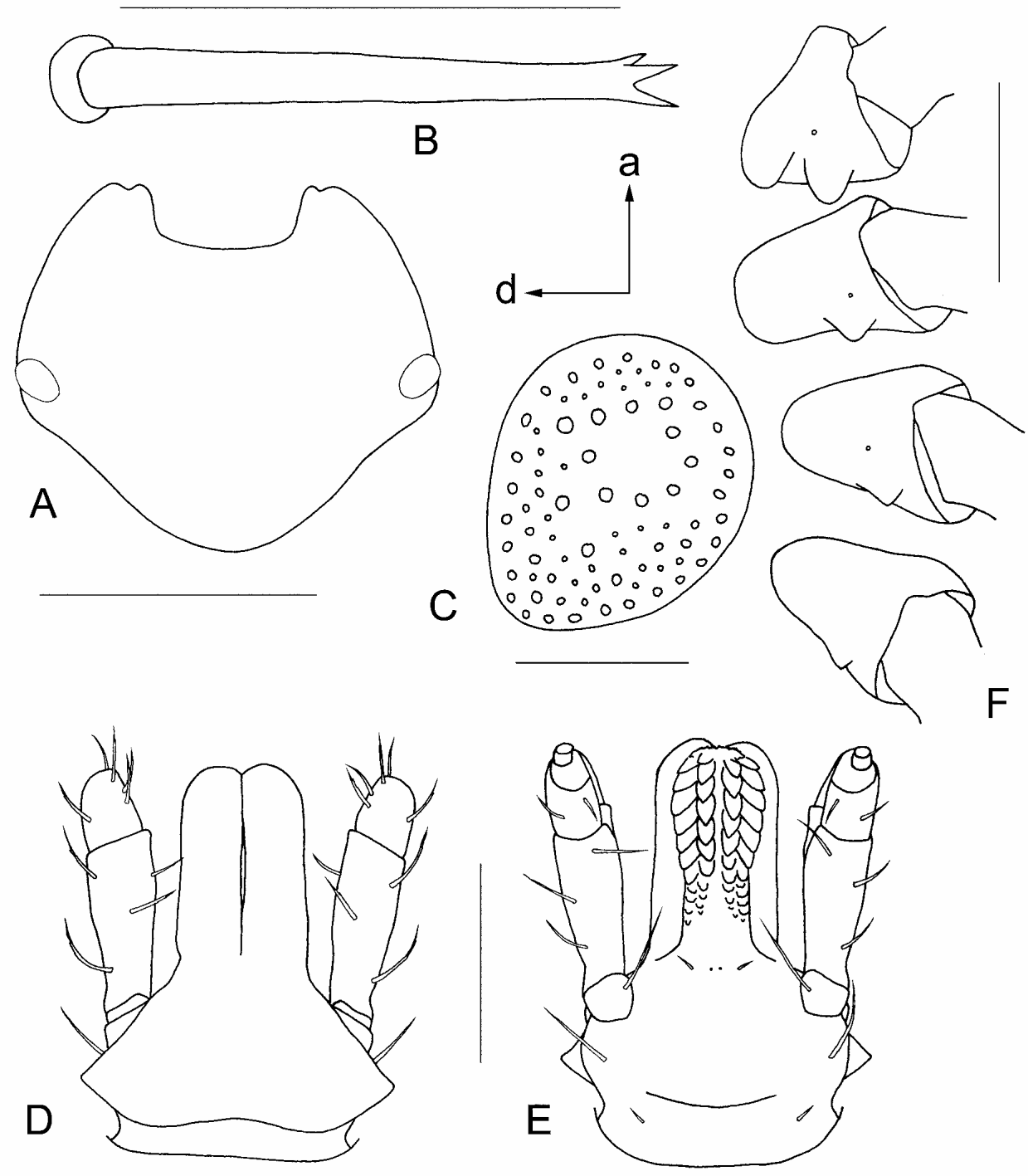

Fig. 6. Hyalomma lusitanicum, nymph. A - scutum; B - seta of alloscutum; C - spiracular plate (a - anterior, d - dorsal); D - gnathosoma dorsally; E - gnathosoma ventrally; F - coxae. All setation has been omitted except drawings D and E where only setae of segment IV have been omitted. Scale bars: A $=400 \mu \mathrm{m} ; \mathrm{B}, \mathrm{C}=50 \mu \mathrm{m} ; \mathrm{D}-\mathrm{F}=200 \mu \mathrm{m}$.

\section{Related species}

The presence of pale marbling on the conscutum of the male and the scutum of the female and the colour pattern on the leg segments place $H$. lusitanicum close to $H$. excavatum and $H$. franchinii.

Males of $H$. lusitanicum can be distinguished from those of $H$. excavatum and $H$. franchinii by a combination of the following characters: conscutum with relatively dense large, medium and small punctations, parma usually not completely developed, perforated portion of dorsal prolongation of spiracular plates moderately narrow, adanal plates relatively broad with concavity in their posterior margin, posterolateral spur of coxa I longer or subequal to posteromedian spur.

Females of $H$. lusitanicum can be distinguished from those of $H$. excavatum and $H$. franchinii by a combina- tion of the following characters: scutum with relatively dense large and medium punctations, genital operculum wide and U-shaped, vestibular part of vagina strongly bulging, posterolateral spur of coxa I longer or subequal to posteromedian spur.

Morphologically the nymph and the larva of $H$. lusitanicum most closely resemble those of $H$. aegyptium.

The nymph of $H$. lusitanicum can be distinguished from that of $H$. aegyptium by its very wide spurs on coxa I, and small spiracular plate with poorly defined dorsal prolongation.

The larva of $H$. lusitanicum can be distinguished from that of $H$. aegyptium only by measurements and their ratios: narrower scutum and basis capituli, shorter and narrower palpi, hypostome and genu. 

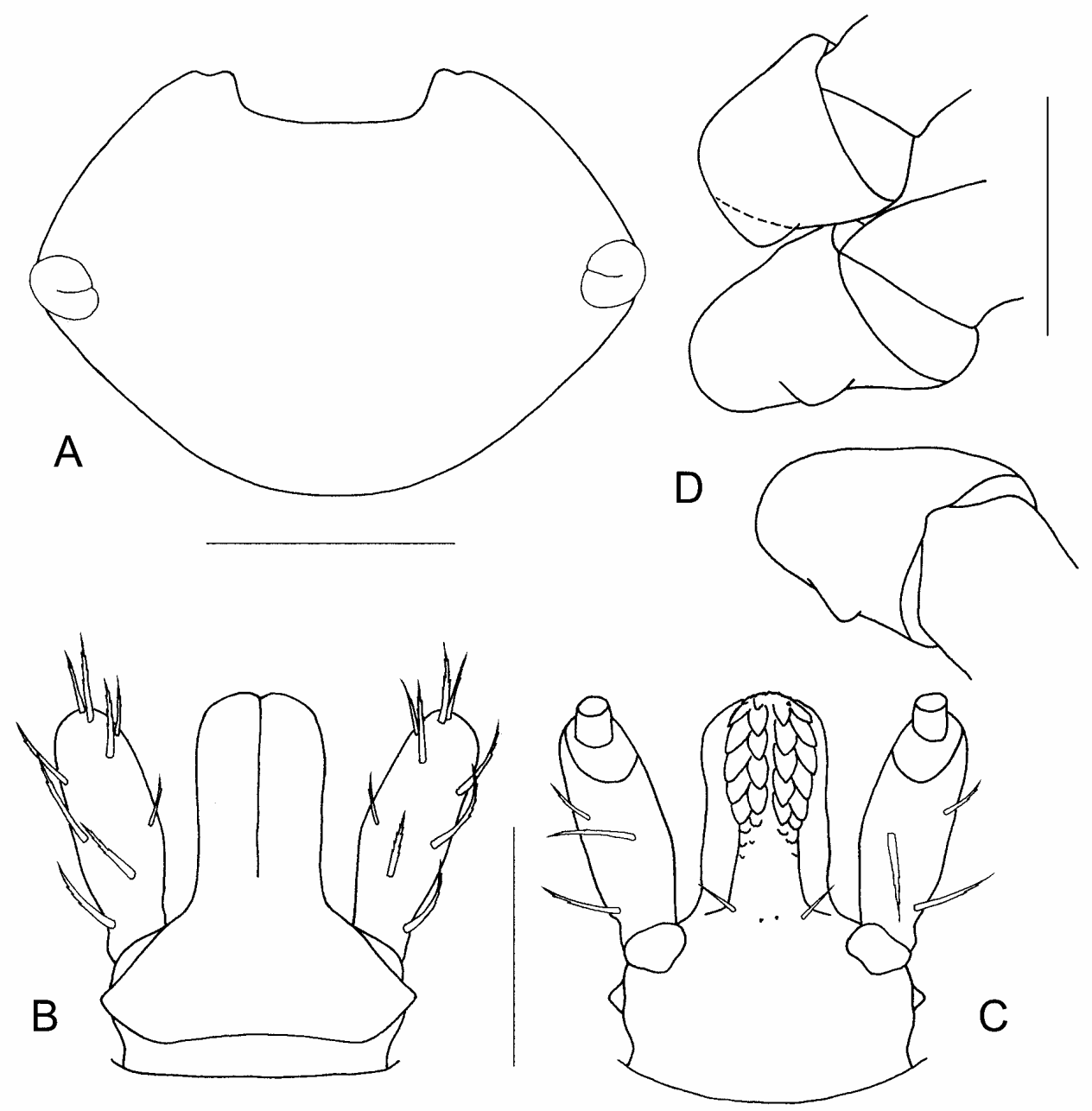

Fig. 7. Hyalomma lusitanicum, larva. A - scutum; B - gnathosoma dorsally; C - gnathosoma ventrally; D - coxae. All setation has been omitted except drawings B and C where only setae of segment IV have been omitted. Scale bars: A $=150 \mu \mathrm{m}$; B-D = $100 \mu \mathrm{m}$.

\section{Hosts}

Hyalomma (E.) lusitanicum is a three-host species (our data; Ouhelli 1994). The chief hosts for the adults are various large and medium-size domestic and wild ungulates, namely cattle, sheep, horses, camels, goats, pigs (both domestic pigs and wild boars), fallow deer, Dama dama (Linnaeus), and red deer, Cervus elaphus Linnaeus. Adults have also been collected from dogs, European rabbits, Oryctolagus cuniculus (Linnaeus), humans and the Eurasian eagle owl, Bubo bubo (Linnaeus) (Tendeiro 1955, 1962, Starkoff 1958, Hoogstraal and Kaiser 1959, Bailly-Choumara et al. 1974, Dias 1994, Manila 1998, our data).

The immature stages of $H$. lusitanicum have been recorded from European rabbits, European hares, Lepus europaeus Pallas, garden dormouse, Eliomys quercinus (Linnaeus), house rat, Rattus rattus (Linnaeus), Western European hedgehog, Erinaceus europaeus Linnaeus, domestic dog, red fox, Vulpes vulpes (Linnaeus), lesser weasel, Mustela nivalis Linnaeus and European polecat,
Mustela putorius Linnaeus (Dias 1994, Perez-Eid and Cabrita 2003). The records of immature stages on domestic birds and cattle (García Fernández and Hueli 1984, Perez-Eid and Cabrita 2003) could be the consequence of erroneous identification, and need to be checked. The most likely hosts of the immature stages of $H$. lusitanicum are various small mammals, such as leporids, rodents and hedgehogs.

There are some records of $H$. lusitanicum from a number of other host species, but because the stages of development were not specified we have not cited them.

\section{Zoogeography}

The distribution of $H$. lusitanicum is restricted to the western part of the Mediterranean subregion of the Palaearctic zoogeographic region. Europe: France, Italy, Portugal and Spain (including Canary Islands); Africa: Algeria and Morocco (Starkoff 1958, Hoogstraal and Kaiser 1959, Morel 1959, Tendeiro 1962, Manila 1998, our data). 
Sympatrically $H$. lusitanicum can be found with $H$. aegyptium, Hyalomma dromedarii Koch, 1844, H. excavatum, Hyalomma impeltatum Schulze et Schlottke, 1930, Hyalomma marginatum marginatum Koch, 1844 and Hyalomma scupense Schulze, 1918 (including $\mathrm{Hy}$ alomma detritum Schulze, 1919).

\section{Disease relationships}

It is almost certain that $H$. lusitanicum is a vector of Theileria annulata (Dschunkowsky et Luhs, 1904) Wenyon, 1926 (Habela et al. 1999, Viseras et al. 1999). The ability of Theileria equi (Laveran, 1901) Mehlhorn et Schein, 1998 to complete its life cycle in H. lusitanicum has also been demonstrated (Zapf and Schein 1994).

\section{Hyalomma (Euhyalomma) franchinii Tonelli Ron- delli, 1932 \\ Figs. 8-14}

Type specimens: The original description was based on specimens ( $\hat{\partial}$, not quantified) from camels and sheep at Tauorga Oasis, Libya, collected by Dr. Regazzi ["Oasi di Tauorga (Tripolitania)", p. 122, Tonelli Rondelli 1932]. The deposition of the type specimens is unknown (Hoogstraal and Kaiser 1958b). In Schulze's collection at the USNTC there is a collection lot la-

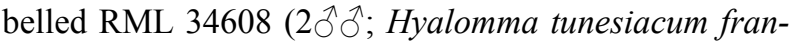
chinii; Tauorga, Tripolitania [Libya]; spring 1931; camels and sheep) of $H$. franchinii, which appears to belong to the original type series.

Synonyms (Camicas et al. 1998):

Hyalomma tunesiacum franchinii Tonelli Rondelli, 1932;

Hyalomma sp. no. 1 near excavatum Hoogstraal, 1956

We consider the most useful descriptions and illustrations of the adults to be those in Tonelli Rondelli (1932), Hoogstraal (1956) and Hoogstraal and Kaiser $(1958 \mathrm{a}, \mathrm{b})$. The larva and nymph have never been described.

\section{Description \\ Male}

Figs. 8, 9A-H, 10A

Conscutum (Fig. 8): length 3.17-4.94 (4.17 \pm 0.34 , $\mathrm{n}=100)$, width $2.02-3.41(2.77 \pm 0.25, \mathrm{n}=100)$, ratio length:width 1.38-1.64 $(1.50 \pm 0.05, \mathrm{n}=100)$; dark redbrown in colour; pale marbling often visible anteriorly; broadly oval in shape; widest slightly posterior to midlength; slight narrowing in region of spiracular plates; cervical and lateral grooves superficial, up to $1 / 3$ length of conscutum; marginal grooves short, furrow-like, extending to posterior $1 / 4$ of conscutum; posteromedian groove separated from parma by smooth area; paramedian grooves well defined; caudal field clearly defined and laterally demarcated by modest ridges; small and large punctations very rare, mainly on caudal and lateral fields; parma usually present; 4 distinct festoons. Genital structures (Fig. 9A) as illustrated. Anal shields (Fig. 9B): 3 pairs; adanal plates long, broad, tapering slightly posterior to median projection, lateral margin slightly

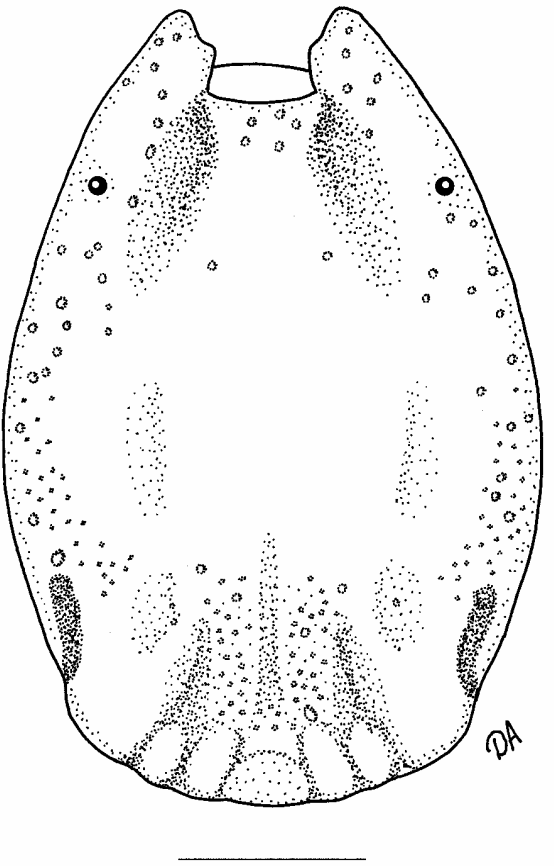

Fig. 8. Hyalomma franchinii, male, conscutum. Scale bar = $1 \mathrm{~mm}$.

convex, anteromedian margin concave, median projection fairly distinct, posteromedian margin straight, posterior margin with concavity; subanal plates variable in size and shape, usually relatively large, triangularly rounded and longitudinally aligned. Ventral sclerotized plaque absent on median, but present on paramedian festoons. Spiracular plate (Fig. 9C): dorsal prolongation long and clearly distinct from body of plate; perforated portion of prolongation straight, curving slightly at its tip, very narrow. Circumspiracular setae sparse.

Basis capituli (Fig. 9D, E): without lateral projections; dorsal posterior margin concave; cornua moderate. Palpi (Fig. 9F): segment I with more than 5 ventromedian setae. Hypostome (Fig. 9G): club-shaped; denticulate portion slightly longer than denticle-free portion.

Coxae (Fig. 9H): posteromedian and posterolateral spurs of coxa I long, posterolateral spur shorter than posteromedian, close together, tapering to apices; coxae II-IV each with a distinct, triangular, posterolateral spur with rounded apex; coxae II and III each with poorly developed, broadly arcuate, posteromedian spur; internal spur on coxa IV distinct, triangular. Diffuse ivorycoloured enamelling on dorsal and lateral surfaces of leg segments; ivory-coloured bands indistinct (Fig. 10A).

Female

Figs. 10B, 11, 12A-G

Scutum (Fig. 11): length 1.88-3.10 (2.52 $\pm 0.26, \mathrm{n}=$ 93), width $1.78-2.77(2.33 \pm 0.21, \mathrm{n}=93)$, ratio length:width $0.97-1.16(1.08 \pm 0.04, \mathrm{n}=93)$; red-brown in colour; comprehensive pale marbling; nearly as long as broad; posterolateral angles prominent; cervical and 


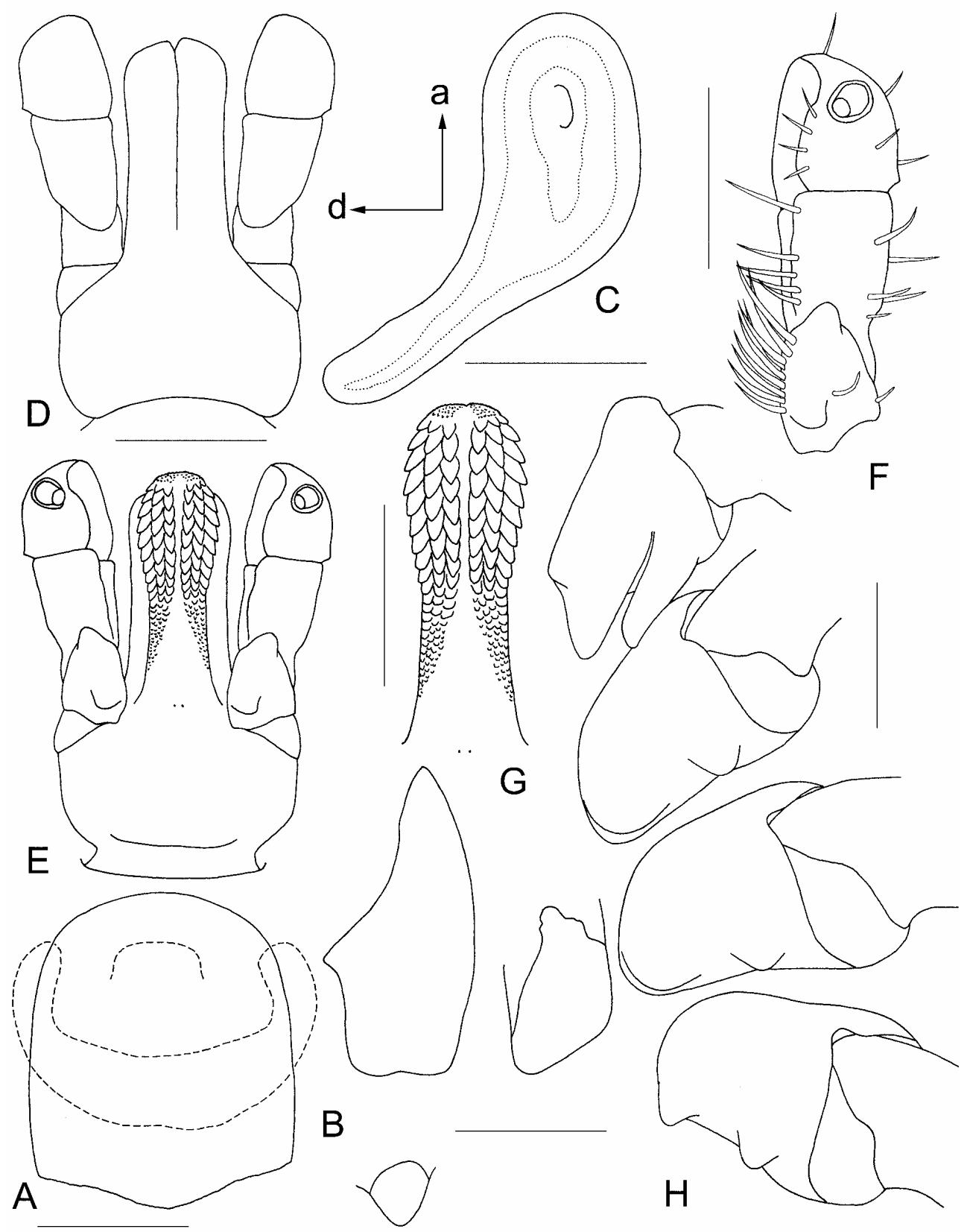

Fig. 9. Hyalomma franchinii, male. A - genital structures; $\mathbf{B}$ - anal plates; $\mathbf{C}$ - spiracular plate (a - anterior, $\mathrm{d}$ - dorsal); $\mathbf{D}$ - gnathosoma dorsally; $\mathbf{E}$ - gnathosoma ventrally; $\mathbf{F}$ - palp ventrally; $\mathbf{G}$ - hypostome; $\mathbf{H}$ - coxae. All setation has been omitted except drawing F where only setae of segment IV have been omitted. Scale bars: $A=200 \mu \mathrm{m} ; \mathrm{B}, \mathrm{D}, \mathrm{E}, \mathrm{H}=500 \mu \mathrm{m} ; \mathrm{C}, \mathrm{F}, \mathrm{G}=400 \mu \mathrm{m}$.

lateral grooves moderately deep, extending to posterior margin of scutum; a few large and medium-sized punctations on lateral, cervical and mainly anterior aspects of central fields, very fine punctations uniformly cover central field of scutum. Genital structures (Fig. 12A): genital aperture wide, broadly V-shaped; vestibular portion of vagina bulging. Spiracular plates (Fig. 12B): perforated portion of dorsal projection curved and relatively narrow. Circumspiracular setae sparse.
Basis capituli (Fig. 12C, D): dorsally lateral projections short, absent ventrally; dorsal posterior margin indented; dorsal cornua inconspicuous. Palpi (Fig. 12E): segment I with more than 5 ventromedian setae. Hypostome (Fig. 12F): club-shaped; denticulate portion slightly longer than denticle-free portion.

Coxae (Fig. 12G): posteromedian and posterolateral spurs of coxa I long, posterolateral spur shorter than posteromedian, tapering to apices, close together; coxae 

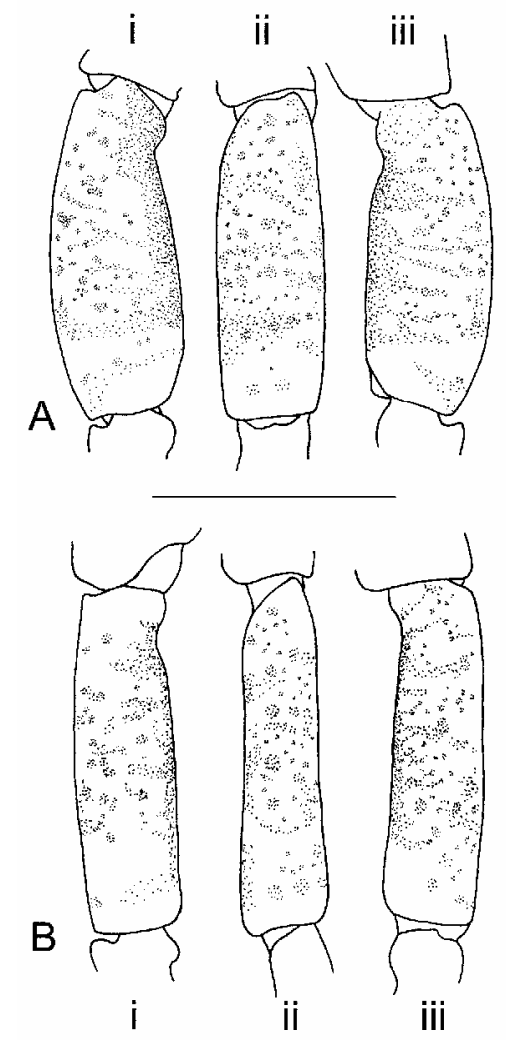

Fig. 10. Hyalomma franchinii, genu IV. A - male: i - lateral view, ii - dorsal view, iii - medial view; $\mathbf{B}$ - female: $\mathrm{i}$ - lateral view, $\mathrm{ii}-$ dorsal view, $\mathrm{iii}-$ medial view. Scale $\mathrm{bar}=1 \mathrm{~mm}$.

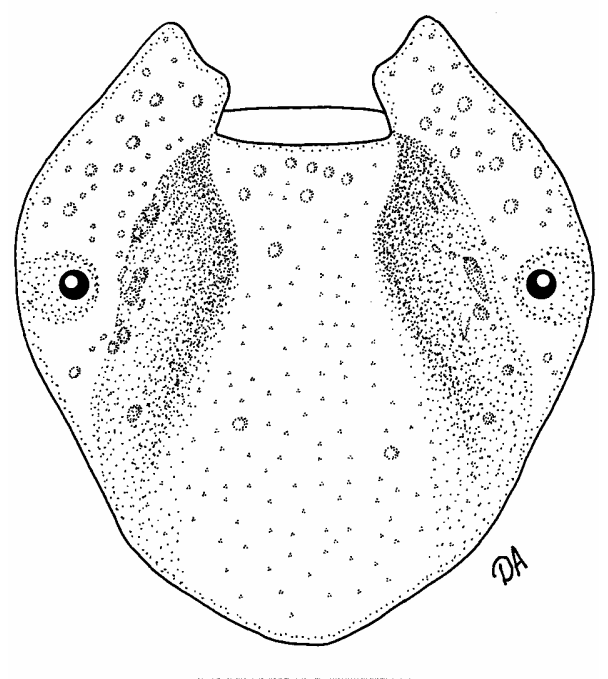

Fig. 11. Hyalomma franchinii, female, scutum. Scale bar $=1$ $\mathrm{mm}$.

II-IV each with distinct, broadly triangular posterolateral spur, with rounded apex; coxae II-IV each with poorly developed, broadly arcuate, posteromedian spur. Other than that ivory-coloured bands are slightly more distinct, colouration of legs similar to that of male (Fig. 10B).

\section{Nymph}

Fig. $13 \mathrm{~A}-\mathrm{F}$

Scutum (Fig. 13A): length 664-720 $(688 \pm 21, \mathrm{n}=6)$, width 696-760 $(723 \pm 23, \mathrm{n}=6)$, ratio length:width $0.92-0.98(0.95 \pm 0.02, \mathrm{n}=6)$, distance between posterior margin of eyes and posterior margin of scutum 304-328 (315 $\pm 10, \mathrm{n}=6)$, width:length ratio of posterior portion of scutum 2.17-2.37 (2.29 $\pm 0.06, \mathrm{n}=6)$; posterior margin of scutum broadly rounded; posterolateral depressions on either side of scutal extremity indistinct. Setae of alloscutum (Fig. 13B): narrowing to apex, without denticles on distal tip. Spiracular plates (Fig. 13C): oval; dorsal prolongation not distinct, short, broad, blunt at apex; submarginal row of perforations complete.

Basis capituli (Fig. 13D, E): length 340-380 (361 \pm $14, \mathrm{n}=5)$; width $308-326(317 \pm 7, \mathrm{n}=6)$, ratio length:width 1.10-1.17 (1.14 $\pm 0.03, \mathrm{n}=5)$. Palpi (segment II) (Fig. 13D, E): length 160-176 $(168 \pm 7, \mathrm{n}=6)$, width 74-77 $(75 \pm 1, \mathrm{n}=6)$, ratio length:width 2.10$2.32(2.22 \pm 0.09, \mathrm{n}=6)$; palpal segment II proximally narrow, gradually expanding distally. Hypostome (Fig. 13E): length $190-220(205 \pm 11, \mathrm{n}=6)$, width 55-64 $(59 \pm 3, \mathrm{n}=6)$, ratio length:width 3.33-3.79 (3.49 \pm $0.16, \mathrm{n}=6$ ); median file with 6 or 7 large denticles; transition of denticulate portion to denticle-free portion abrupt; denticulate portion nearly twice as long as denticle-free portion.

Coxae (Fig. 13F): coxa I with long, narrow, subtriangular spurs, median spur shorter than lateral; coxae IIIV each with moderate spur, spurs conspicuously decreasing in size from coxae II to IV; coxal pore present.

Larva

Fig. 14A-D

Scutum (Fig. 14A): length 260-280 (268 $\pm 6, \mathrm{n}=38)$, width $348-388(367 \pm 8, \mathrm{n}=40)$, ratio length:width $0.71-0.77(0.73 \pm 0.01, \mathrm{n}=38)$, distance from posterior margin of eyes to posterior margin of scutum 104-120 (111 $\pm 4, \mathrm{n}=38)$, width:length ratio of posterior portion $3.10-3.54(3.30 \pm 0.10, n=38)$. Portion of scutum posterior to eyes nearly equal to $1 / 2$ of scutal length; posterior margin of scutum broadly rounded; posterolateral depressions indistinct.

Basis capituli (Fig. 14B, C): width 122-138 (129 \pm 4 , $\mathrm{n}=39$ ); subhexagonal dorsally; subrectangular ventrally; apex of dorsolateral projections directed laterally; dorsolateral projections distinct and acute from ventral aspect. Palpi (segments II and III) (Fig. 14B, C): length 88-96 $(92 \pm 2, \mathrm{n}=39)$, width $38-42(40 \pm 1, \mathrm{n}=$ $33)$, ratio length:width $2.19-2.41(2.29 \pm 0.05, \mathrm{n}=33)$. Hypostome (Fig. 14C): length $78-88(82 \pm 2, \mathrm{n}=30)$, width $23-26(24 \pm 1, \mathrm{n}=30)$, ratio length:width 3.20 $3.58(3.38 \pm 0.08, \mathrm{n}=30)$; median file with 4 or 5 large denticles; transition of denticulate portion to denticlefree portion abrupt; denticulate portion approximately $1 / 2$ of hypostome length.

Coxae (Fig. 14D): spurs of coxae I-III indistinct, either absent or extremely short and arcuate on coxa I, absent on coxa II, absent or fold-like on coxa III. Genua 

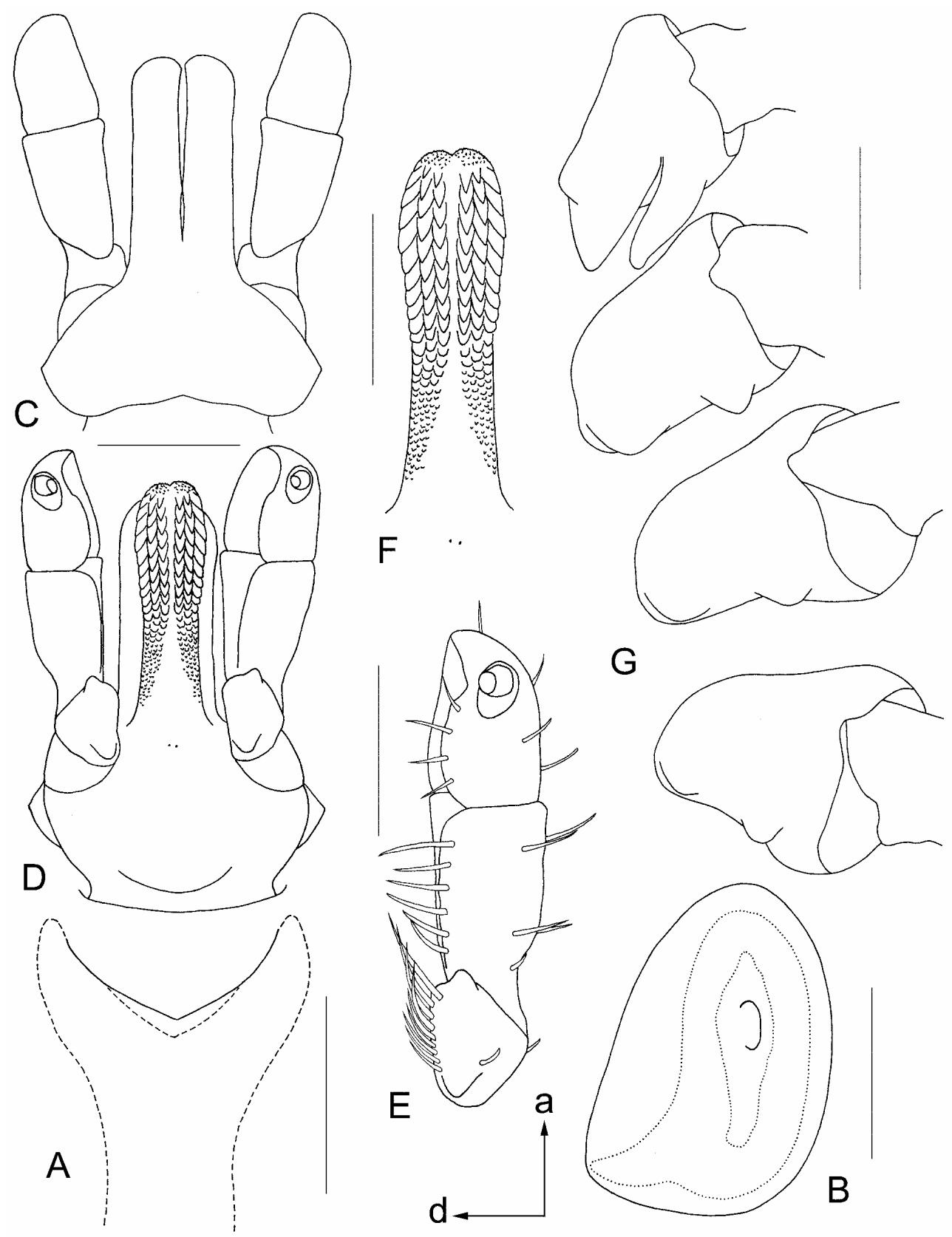

G
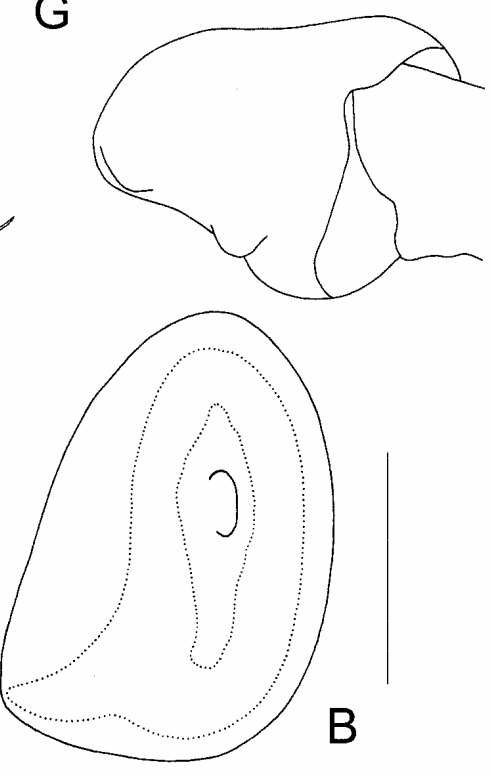

Fig. 12. Hyalomma franchinii, female. A - genital structures; B - spiracular plate (a - anterior, $\mathrm{d}$ - dorsal); $\mathbf{C}$ - gnathosoma dorsally; D - gnathosoma ventrally; $\mathbf{E}$ - palp ventrally; $\mathbf{F}$ - hypostome; $\mathbf{G}$ - coxae. All setation has been omitted except drawing E where only setae of segment IV have been omitted. Scale bars: A $=200 \mu \mathrm{m} ; \mathrm{B}, \mathrm{E}, \mathrm{F}=400 \mu \mathrm{m} ; \mathrm{C}, \mathrm{D}, \mathrm{G}=500 \mu \mathrm{m}$.

I: length $122-134(127 \pm 3, \mathrm{n}=40)$, width $42-50(45 \pm$ $2, \mathrm{n}=27)$, ratio length:width $2.60-3.05(2.80 \pm 0.10, \mathrm{n}$ =27).

\section{Related species}

The presence of pale marbling on the conscutum of the male and the scutum of the female and the colour pattern of the leg segments place $H$. franchinii close to $H$. excavatum and $H$. lusitanicum.

Males of $H$. franchinii are distinguished from those of $H$. excavatum and $H$. lusitanicum by a combination of the following characters: very smooth conscutum with few punctations, perforated portion of dorsal prolongation of spiracular plates very narrow, adanal plates relatively broad with indentation on their posterior margin, posterolateral spur of coxa I distinctly shorter than posteromedian spur.

Females of $H$. franchinii can be distinguished from those of $H$. excavatum and $H$. lusitanicum by a combination of the following characters: scutum very smooth with few punctations, genital operculum wide and V- 


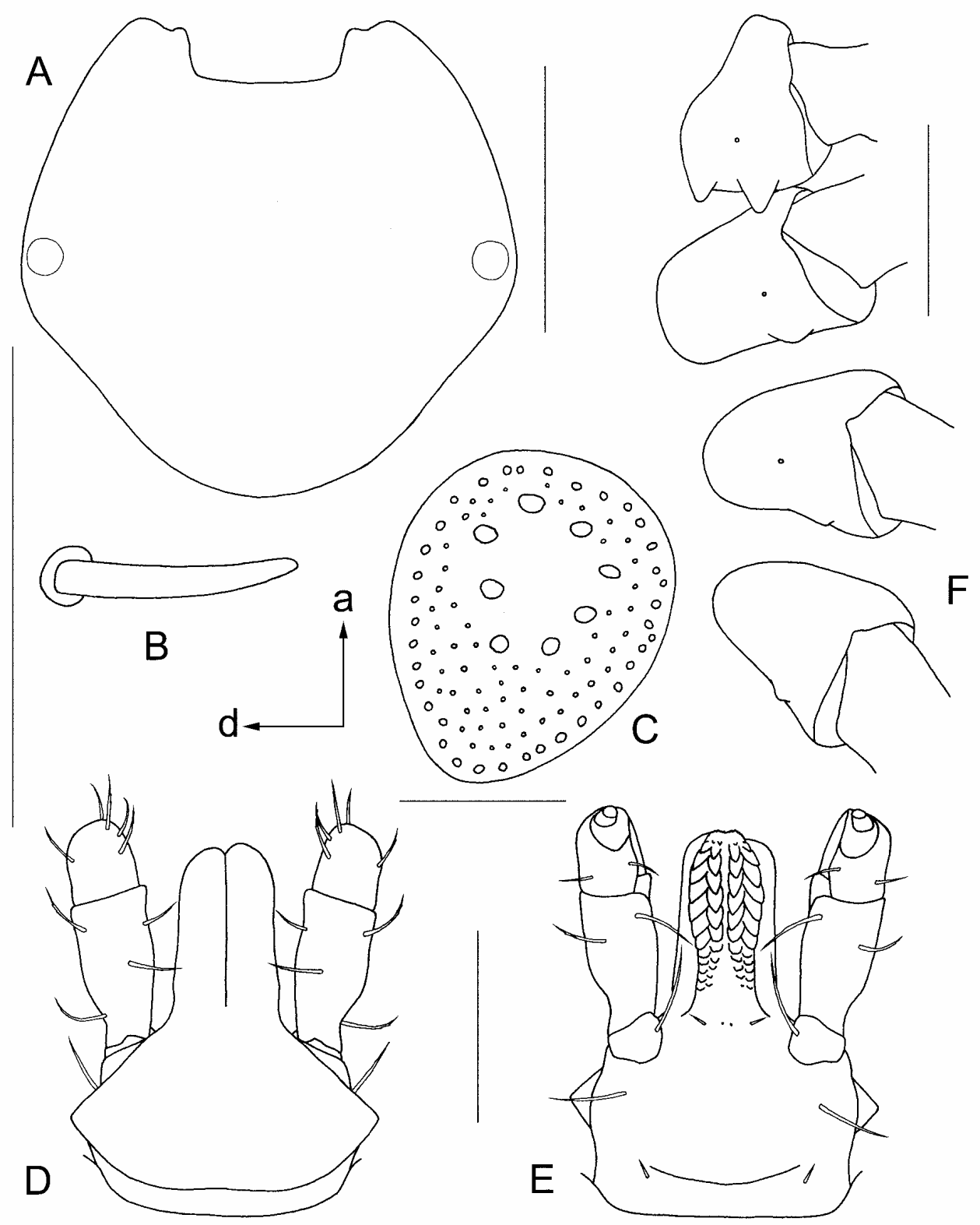

Fig. 13. Hyalomma franchinii, nymph. A - scutum; B - seta of alloscutum; C - spiracular plate (a - anterior, $d-d o r s a l)$; $\mathbf{D}$ - gnathosoma dorsally; E - gnathosoma ventrally; F - coxae. All setation has been omitted except drawings D and E where only setae of segment IV have been omitted. Scale bars: A $=400 \mu \mathrm{m} ; \mathrm{B}, \mathrm{C}=50 \mu \mathrm{m} ; \mathrm{D}-\mathrm{F}=200 \mu \mathrm{m}$.

shaped, vestibular part of vagina bulging, posterolateral spur of coxa I clearly shorter than posteromedian spur.

Morphologically the nymph and the larva of $H$. franchinii most closely resemble those of $H$. aegyptium.

The nymph of $H$. franchinii can be differentiated from that of $H$. aegyptium by the setae of the alloscutum, which are without apical denticles, a small spiracular plate with poorly defined dorsal prolongation and by measurements and their ratios: larger scutum, shorter and broader palpi and shorter hypostome.

The larva of $H$. franchinii can be distinguished from that of $H$. aegyptium by indistinct spurs on coxae I-III, and by measurements and their ratios: narrower scutum and basis capituli, shorter palpi, shorter and narrower hypostome and genu.

\section{Hosts}

Hyalomma (E.) franchinii is a three-host species (Hoogstraal and Kaiser 1958b). Its adults have been recorded only from domestic mammals such as camels, cattle, donkeys and sheep; but a single male has been collected from a land tortoise (Hoogstraal and Kaiser 1958b, 1960, our data). Immature stages have been collected from the lizards Acanthodactylus boskianus (Daudin), Acanthodactylus schreiberi Boulenger, Acanthodactylus scutellatus (Audouin) and Agama mutabilis 

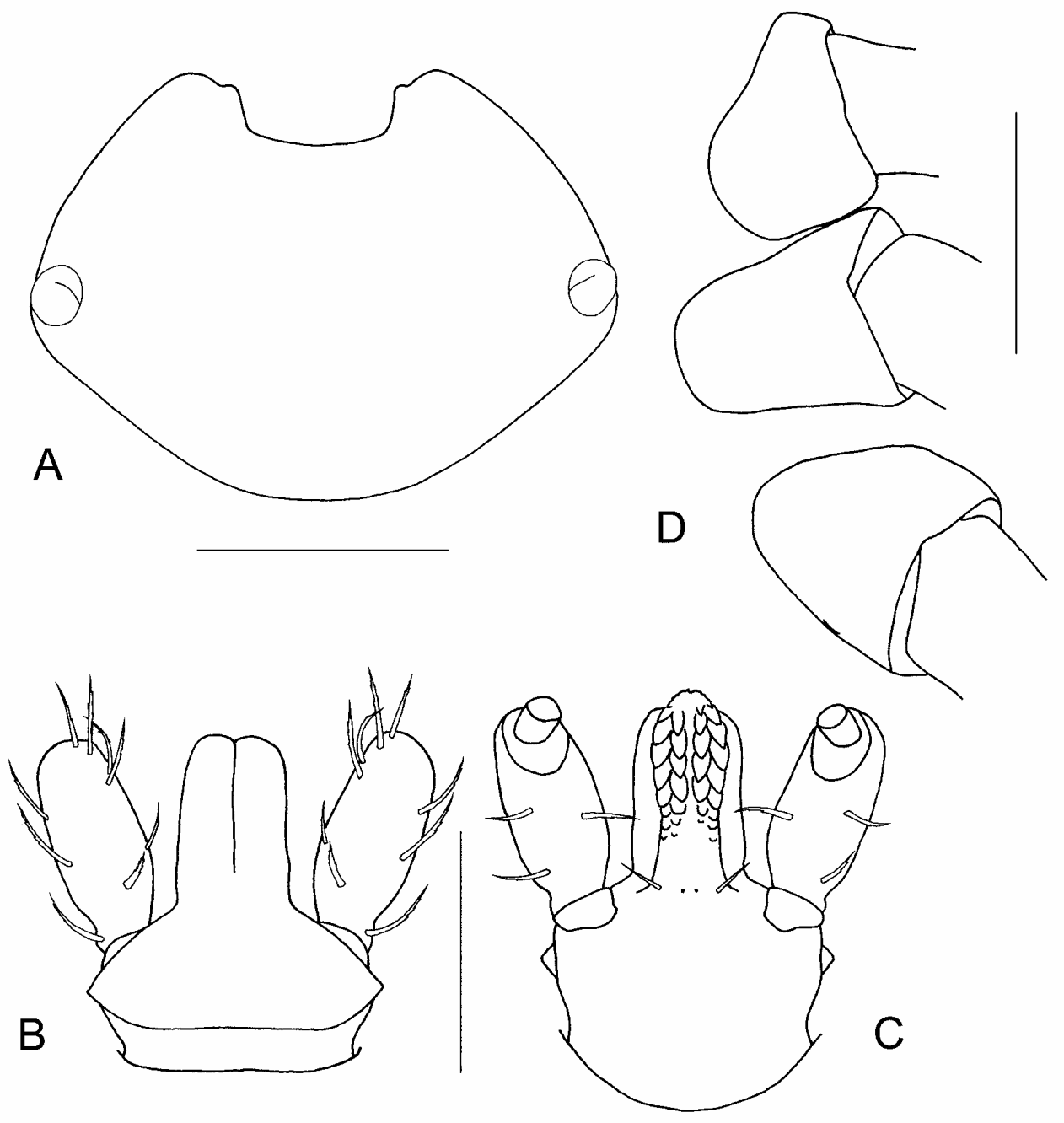

Fig. 14. Hyalomma franchinii, larva. A - scutum; B - gnathosoma dorsally; C - gnathosoma ventrally; D - coxae. All setation has been omitted except drawings B and C where only setae of segment IV have been omitted. Scale bars: A $=150 \mu \mathrm{m}$; B-D = $100 \mu \mathrm{m}$.

Merrem, and from the golden spiny mouse, Acomys russatus (Wagner) (Hoogstraal and Kaiser 1958a, Cwilich and Hadani 1962, our data).

\section{Zoogeography}

The known distribution of $H$. franchinii is restricted to the eastern part of the Mediterranean subregion of the Palaearctic zoogeographic region. Africa: Egypt, Libya and Tunisia; Asia: Israel (Hoogstraal 1956, Hoogstraal and Kaiser 1958a, b, 1960, Cwilich and Hadani 1962 , Bouattour et al. 1999, our data).

Sympatrically $H$. franchinii can be found with $H$. aegyptium, $H$. anatolicum, $H$. dromedarii, H. excavatum, H. impeltatum, H. marginatum marginatum, Hyalomma marginatum rufipes Koch, 1844, Hyalomma marginatum turanicum Pomerantzev, 1946 and H. scupense (including $H$. detritum).

\section{Disease relationships}

The relationships of disease-inducing agents with $H$. (E.) franchinii have not been investigated.
Acknowledgements. We are most grateful to Drs. N.A. Filippova (Zoological Institute, Russian Academy of Sciences, Saint Petersburg, Russia), D. Summers (Field Museum of Natural History, Chicago, USA), J.B. Walker (South Africa), H. André (Royal Museum for Central Africa, Tervuren, Belgium) and Ms. H. Heyne (Gertrud Theiler Tick Museum, Onderstepoort Veterinary Institute, South Africa) for making specimens available for study. We are also indebted to Dr. A. Hall (Laboratory for Microscopy and Analysis, University of Pretoria, South Africa) and Dr. W. Krissinger (Georgia Southern University, USA) for their kind help with scanning electron microscopy. I.G. Horak's participation in this project has been facilitated by the Integrated Consortium on Ticks and Tick-borne Diseases (ICTTD-3), financed by the International Cooperation Program of the European Union through Coordination Action Project No. 510561. 


\section{REFERENCES}

APANASKEVICH D.A. 2003: Differentiation of closely related species Hyalomma anatolicum and $H$. excavatum (Acari, Ixodidae) based on a study of all life cycle stages, throughout their entire geographical range. Parazitologiya 37: 259-280. (In Russian.)

APANASKEVICH D.A., HORAK I.G. 2006: The genus Hyalomma Koch, 1844. I. Reinstatement of Hyalomma (Euhyalomma) glabrum Delpy, 1949 (Acari, Ixodidae) as a valid species with a redescription of the adults, the first description of its immature stages and notes on its biology. Onderstepoort J. Vet. Res. 73: 1-12.

Bailly-Choumara H., Morel P., Rageau J. 1974: Première contribution au catalogue des tiques du Maroc (Acari, Ixodoidea). Bull. Soc. Sci. Nat. Phys. Maroc 54: 71-80.

Bouattour A., DARGhouth M.A., DAOUd A. 1999: Distribution and ecology of ticks (Acari: Ixodidae) infesting livestock in Tunisia: an overview of eight years field collections. Parassitologia 41: 5-10.

Camicas J.-L., Hervy J.-P., AdAm F., Morel P.-C. 1998: The Ticks of the World (Acarida, Ixodida). Nomenclature, Described Stages, Hosts, Distribution. ORSTOM éditions, Paris, 233 pp.

CWILICH R., HADANI A. 1962: The identification of the tick Hyalomma franchinii, Tonelli-Rondelli, 1932. Refu. Vet. 19: 178180.

DELPY L.P. 1949: Essai critique de synonymie du genre Hyalomma C.L. Koch 1844 depuis Linné, 1758. Ann. Parasitol. Hum. Comp. 24: 464-494.

DIAS J.A.T.S. 1994: As carraças (Acarina - Ixodoidea) da Península Ibérica. Algumas considerações sobre a sua biogeografia e relacionamento com a ixodofauna Afropaleárctica e Afrotropical. Estud. Ensai. Doc. 158, 163 pp.

FELDMAN-MUHSAM B. 1954: Revision of the genus Hyalomma. I. Description of Koch's types. Bull. Res. Counc. Israel 4: 150 170.

FELDMAN-MuHSAM B. 1962: Revision of the genus Hyalomma. III. H. lusitanicum Koch and H. anatolicum K. Parasitology 52: 211-219.

GARCIA FERNANDEZ P., HUEli L.E. 1984: Garrapatas (Acarina Ixodidae) parasitas del ganado bovino en el sur de España. Identificación, distribución geográfica y estacional. Rev. Ibér. Parasitol. 44: 129-138.

Habela M., Rol J.A., ANTON J.M., PENA J., CORChERO E., VAN HAM I., JONGEJAN F. 1999: Epidemiology of Mediterranean theileriosis in Extremadura region, Spain. Parassitologia 41: 47-51.

HOOGSTRAAL H. 1956: African Ixodoidea. I. Ticks of the Sudan (with special reference to Equatoria Province and with preliminary reviews of the genera Boophilus, Margaropus, and Hyalomma). Department of the Navy, Washington D.C., 1101 pp.

HOOGSTRAAL H., KAISER M.N. 1958a: Observations on Egyptian Hyalomma ticks (Ixodoidea, Ixodidae). I. Parasitism of lizards by nymphs. Ann. Entomol. Soc. Am. 51: 7-12.

HoOgstraAl H., KAISER M.N. 1958b: Observations on Egyptian Hyalomma ticks (Ixodoidea, Ixodidae). 4. Identity, distribution, and hosts of H. franchinii Tonelli-Rondelli (new combination). Systematic status of H. tunesiacum Sc. \& Sc. and its subspecies. Ann. Entomol. Soc. Am. 51: 397-400.
HoOgStraAl H., KAISER M.N. 1959: Observations on Egyptian Hyalomma ticks (Ixodoidea, Ixodidae). 5. Biological notes and differences in identity of $H$. anatolicum and its subspecies anatolicum Koch and excavatum Koch among Russian and other workers. Identity of H. lusitanicum Koch. Ann. Entomol. Soc. Am. 52: 243-261.

HoOgStraAl H., KAISER M.N. 1960: Observations on ticks (Ixodoidea) of Libya. Ann. Entomol. Soc. Am. 53: 445-457.

KocH C.L. 1844: Systematische Übersicht über die Ordnung der Zecken. Arch. Naturgesch. 10: 217-239.

MANILA G. 1998: Fauna d'Italia. Acari, Ixodida. Edizioni Calderini, Bologna, $280 \mathrm{pp}$

MOREL P.C. 1959: Les Hyalomma (Acariens, Ixodidae) de France. Ann. Parasitol. Hum. Comp. 34: 552-555.

NEUMANN G. 1899: Revision de la famille des Ixodidés. (3e mémoire). Mém. Soc. Zool. Fr. 12: 107-294.

NEUMANN G. 1901: Revision de la famille des Ixodidés. (4e mémoire). Mém. Soc. Zool. Fr. 14: 249-372.

OuHELli H. 1994: Comparative development of Hyalomma marginatum (Koch, 1844), H. detritum (Schulze 1919), H. anatolicum excavatum (Koch, 1844), H. lusitanicum (Koch, 1884), H. dromedarii (Koch, 1844) under laboratory conditions. Acta Parasitol. 39: 153-157.

Perez-Eid C., CABrita J. 2003: La larve et la nymphe de Hyalomma (Hyalomma) lusitanicum Koch, 1844 (Acari: Ixodida): description morphologique, habitats, hotes. Acarologia 43: 327-335.

SCHUlzE P., SCHLOTTKE E. 1930: Bestimmungstabellen für das Zeckengenus Hyalomma Koch s. str. Sitzungsber. Abh. Naturforsch. Ges. Rostock 2: 32-46.

SENEVET G. 1922: Les espèces algériennes du genre Hyalomma. Arch. Inst. Pasteur Afr. Nord 2: 392-418.

SENEVET G. 1925: Description des nymphes de Rhipicephalus bursa et de Hyalomma lusitanicum avec un tableau pour la détermination des nymphes des Ixodidés algériens. Arch. Inst. Pasteur Algérie 3: 59-63.

SENEVET G. 1928: Clé pour la détermination des larves d'Ixodidés trouvées sur les bovins en Algérie. Arch. Inst. Pasteur Algérie 6: 42-46.

STARKOFF O. 1958: Ixodoidea d'Italia. Il Pensiero Scientifico, Roma, 385 pp.

TENDEIRO J. 1955: Sobre alguns ixodídeos dos géneros Hyalomma C.L. Koch 1844 e Aponomma Neumann 1899. Bol. Cult. Guiné Port. 10: 319-461.

TENDEIRO J. 1962: Revisão sistemática dos Ixodídeos Portugueses. Bol. Pecu. 30: 5-131.

TONELli RonDelli M. 1932: Hyalomma nuovi delle colonie Italiane. Atti Soc. Ital. Sci. Nat. 71: 119-125.

Viseras J., HUELI L.E., ADROHER F.J., GARCIA-FERNANDEZ P. 1999: Studies on the transmission of Theileria annulata to cattle by the tick Hyalomma lusitanicum. J. Vet. Med., Series B, 46: 505-509.

ZAPF F., SCHEIN E. 1994: New findings in the development of Babesia (Theileria) equi (Laveran, 1901) in the salivary glands of the vector ticks, Hyalomma species. Parasitol. Res. 80: 543-548. 